\title{
O Centro Brasileiro de Pesquisas Educacionais: criação, intervenção e legitimação nos planos regional, nacional e internacional (1955-1964). Fernando Cesar Ferreira Gouvea ${ }^{I}$
}

\section{RESUMO}

O CENTRO BRASILEIRO DE PESQUISAS EDUCACIONAIS: CRIAÇÃO, INTERVENÇÃO E LEGITIMAÇÃO NOS PLANOS REGIONAL, NACIONAL E INTERNACIONAL (1955-1964)

O presente trabalho tem como objeto de estudo o Centro Brasileiro de Pesquisas Educacionais (CBPE), a sua gênese e o seu processo de intervenções planejadas com a perspectiva de legitimação da instituição nos planos regional, nacional e internacional no campo da educacional em diálogo fecundo com as Ciências Sociais no período de 1955 a 1964 - gestão do intelectual Anísio Teixeira. A compreensão das estratégias que foram acionadas para a legitimação do CBPE no plano nacional e, posteriormente, no plano internacional são os objetivos deste escrito, trabalhando com as seguintes problematizações: Como a instituição conseguiu obter a legitimação necessária para as intervenções realizadas nos diferentes planos? As relações e compromissos assumidos no plano internacional ocasionaram problemas institucionais no âmbito nacional? A tentativa de respostas a tais questões terá como fontes as publicações oficiais do Ministério da Educação e Cultura como a Revista Educação e Ciências Sociais e o Boletim Mensal do Centro Brasileiro de Pesquisas Educacionais que ainda não foram explorados com aprofundamento no campo da historiografia da Educação Brasileira. Por fim, cabe explicitar que a metodologia utilizada repousa na pesquisa de caráter documental e histórico, especialmente no que concerne à história cultural, na perspectiva de estudar a atuação do maior centro de pesquisas educacionais da América Latina nos anos 1950 e 1960 .

Palavras-chave: História da Educação; Instituições de Pesquisa; Ciências Humanas e Ciências Sociais; Centro Brasileiro de Pesquisas Educacionais, MEC- 1955-1964.

1Professor adjunto do Instituto de Educação da UFRRJ e professor do Programa de Pós-graduação em Educação, Contextos Contemporâneos e Demandas Populares da mesma Universidade. Membro do Grupo de Estudos e Pesquias da História da Universidade Federal Rural do Rio de Janeiro, das Instituições Educativas e dos Movimentos Sociais -GEPHUR. 


\begin{abstract}
EDUCATIONAL RESEARCH BRAZILIAN CENTER: CREATION, INTERVENTION AND LEGITIMACY IN A REGIONAL, NATIONAL AND INTERNATIONAL VIEW (1955-1964)
\end{abstract}

This paper aims to study Educational Research Brazilian Center (ERBC), in genesis and planned interventions process with the prospect of legitimation at the regional, national and international level in an education field in fruitful dialogue with Social Sciences during the period 1955-1964 - intellectual Teixeira management. Understanding strategies that have been triggered for the ERBC legitimization nationally and then internationally are goals of this paper, working with the following problematizations: How the institution was able to obtain the necessary legitimacy for interventions in different planes? Relationships and commitments at the international has caused institutional troubles nationally? Trying to answer these questions will have as sources the official publications of the Ministry of Education and Culture as Education and Social Sciences Journal and Monthly Bulletin of the Educational Research Brazilian Centerthat has not been explored in depth in the field of historiography of Brazilian Education. Finally, it is clear that the methodology used in the research rests documentary character and history, especially in relation to cultural history, from the perspective of studying the role of higher education research center in Latin America in the 1950s and 1960s. Keywords: History of Education; Reasearch Instituitions; Human Sciencies and Social Sciences; Educational Research Brazilian Center, MEC 1955-1964.

\title{
ENTRE OBJETOS, OBJETIVOS E PERCURSOS: A HISTÓRIA DO CENTRO BRASILEIRO DE PESQUISAS EDUCACIONAIS
}

O Centro Brasileiro de Pesquisas Educacionais foi criado pelo Decreto 38.460 de dezembro de 1955, tendo como localização a cidade do Rio de Janeiro e mais cinco Centros Regionais de Pesquisa Educacional: São Paulo, Minas Gerais, Pernambuco, Rio Grande do Sul e Bahia. Efetivamente, o ano de 1957 representou um período de organização geral da instituição tanto no que concerne aos locais de instalação quanto à contratação de profissionais suficientes para dar as mínimas condições de funcionamento a estes órgãos de pesquisas.

Este trabalho busca evidenciar que a legitimação do CBPE emerge como móvel ligado de forma inextricável às suas ações e às suas intervenções operadas no campo das ciências sociais em parceria com as seguintes instituições pan-americanas: Organização dos Estados Americanos (OEA)²; Conselho de Educação Superior para as Repúblicas Americanas (CHEAR)³; o Programa de Assistência Brasileiro-Americana no Ensino Elementar (PABAEE) ${ }^{4}$ e a Universidade do Chile.

2 Criada em 1958. Tem como sede os Estados Unidos da América.

3 Abreviatura em inglês do Council on Higher Education in the American Republics que foi criado em 1958 com sede rotativa no âmbito da área Pan-americana.

4 Programa de Assistência Brasileiro-Americana no Ensino Elementar. Convênio firmado entre o Brasil e os Estados da América. Com direção compartilhada e sede no Brasil, cidade de Belo Horizonte.

Ci. Huma. e Soc. em Rev. Seropédica, v. 35 n2, jul. dez., 191-213, 2013. 
Tais parcerias ocorreram com financiamentos da UNESCO, mais especificamente através do Projeto Maior $\mathrm{n}^{\circ} 1^{5}$. Desta forma, cabe a compreensão das estratégias que foram acionadas para a consubstanciação e legitimação do projeto cebepiano (CERTEAU, 2004; GOUVÊA, 2009).

As articulações demandaram um intenso trabalho de legitimação do CBPE tanto no âmbito nacional quanto no plano latino-americano. Mas, como legitimar uma instituição pública que fora pensada para ter vida independente das inflexões do Estado? Como agir com eficiência dentro de um modelo de Estado complexo? Como, enfim, intervir de maneira exemplar num sistema educacional ainda em fase de estruturação? A tentativa de respostas a tais questões terá a contribuição dos impressos pedagógicos como instrumentos de legitimação institucional na área das Ciências Humanas e das Ciências Sociais. Especificamente, neste estudo, será examinado o papel do Boletim Mensal do Centro Brasileiro de Pesquisas Educacionais na tentativa de legitimação do CBPE no âmbito do Ministério da Educação e Cultura (MEC) e sob o comando do Instituto Nacional de Estudos Pedagógicos (INEP) ${ }^{6}$ no período de 1955 a 1964.

Parto do pressuposto que foi colocada em jogo uma rede de impressos (GOUVÊA, 2001, 2012) para tal processo de legitimação que possibilitou o acionamento de três estratégias para a consubstanciação deste projeto: a estratégia de articulação, por serem os impressos veículos de informação de uma instituição que almejou o máximo envolvimento de todos os atores; a estratégia de intervenção haja vista a possibilidade de pensar os impressos enquanto vozes oficiais da instituição que buscou organizar a sua representação institucional nos planos internacional, nacional e regional e, por fim, a estratégia de legitimação em que os impressos são escrituras que buscaram imprimir e erigir a memória de um determinado grupo de poder como hegemônica e paradigmática no campo educacional e, no caso do CBPE, também no campo das Ciências Sociais.

Assim, a materialidade do impresso não está restrita ao suporte, é também transporte de textos por rotas múltiplas; ponto de partida e, ao mesmo tempo, de chegada para alcançar o leitor. Deste modo, insere-se esta pesquisa no bojo da história cultural e da história política e procura estabelecer possibilidades de compreensão do período em tela para a historiografia da educação brasileira, lançando luzes no processo de estabelecimento de parcerias institucionais, em especial com o acompanhamento das atividades do CBPE e de dois centros

5 O Projeto Maior n ${ }^{\circ} 1$ foi apresentado durante a "Conferência Regional sobre Educação Primária Gratuita e Obrigatória na América Latina” em abril de 1956. Um dos objetivos do projeto era o aperfeiçoamento em nível universitário de especialistas da educação a ser realizado pelo Centro Regional de Pesquisas Educacionais de São Paulo e pela Universidade do Chile.

6 Criado em 1937, em funcionamento em 1938, sob a direção de Lourenço Filho. Teve como sede a cidade do Rio de Janeiro, então Distrito Federal. 
regionais específicos: São Paulo e Bahia. A saber, os dois centros que mais se aproximaram e contribuíram para a tessitura de uma rede internacional e nacional na área das pesquisas educacionais e sociais (CHARTIER, 1990; RÉMOND, 2003). Tal acompanhamento terá como base o Boletim Mensal do Centro Brasileiro de Pesquisas Educacionais.

\section{A ESTRUTURA DO BOLETIM MENSAL DO CENTRO BRASILEIRO DE PESQUISAS EDUCACIONAIS: TERRITÓRIOS E SEÇÕES}

Certamente, deve causar estranheza a utilização da palavra 'territórios' ao lado da palavra 'seções' no momento de apresentação da estrutura do Boletim Mensal do Centro Brasileiro de Pesquisas Educacionais (BMCBPE). A leitura do objeto do objeto estudo trouxe uma dificuldade em estabelecer uma separação entre aquilo que poderia chamar de seção e aquilo que deveria assinalar como aparecimento pontual. Durante bom tempo esta questão foi um obstáculo a ser enfrentado. Deste modo, foi necessário operar com duas classificações que entendo oportunas para lidar com o BMCBPE: a divisão do boletim em 'territórios' e 'seções'. Não se trata de qualquer novidade metodológica, mas, sim, de uma possibilidade de trabalho. Os 'territórios' estão divididos entre o CBPE e os CRPEs. Dentro de cada um destes 'territórios' estão localizadas as seções.

Apenas como justificativa da divisão defendida, urge salientar que o BMCBPE tinha como função principal divulgar os estudos e pesquisas realizados pelo Centro e pelos Centros Regionais o que expressa uma 'divisão territorial' das matérias a serem veiculadas pelo impresso e, mais do que isto, a resolução da Comissão Consultiva que criou o boletim permitiu a seleção prévia do material que de fato seria publicado. Tal preceito originou uma rotatividade das 'seções' dentro de cada 'território'. Cabe exemplificar: Muitas vezes, dentro do 'território' destinado aos CRPEs a 'seção' CRPE-MG não se fez presente nas páginas do boletim. Ao menos, três motivos podem estar presentes nesta ausência: o CRPE-MG não enviou as notícias; as notícias chegaram com atraso ou não consignavam pontos-chave do projeto editorial. Por isto, enquanto os 'territórios' representam a permanência, as 'seções' se apresentam como as partes móveis do projeto deste estudo sobre o BMCBPE (GOUVÊA, 2008, 2012a).

Apesar de a legislação conferir existência ao CBPE e aos Centros Regionais a partir de dezembro de 1955 é forçoso admitir que, além do Centro Brasileiro, o único Centro Regional que apresentou atividade regular foi o CRPE de São Paulo por conta do convênio entre o INEP e a Universidade de São Paulo (USP). Assim, "na prática, além do Diretor 
e do Conselho, quase todas as pessoas envolvidas com as atividades do Centro (regional), no período de 1956 a 1961, eram ou haviam sido vinculadas à Faculdade de Filosofia da USP, seja como professores, alunos ou funcionários" (FERREIRA, 2001, p. 13).

A fim de possibilitar o entendimento das análises sobre os 'territórios' e 'seções' do BMCBPE, segue o quadro 01 .

\section{QUADRO 01}

TERRITÓRIOS OCUPADOS PELO CBPE E PELOS CRPEs (1957 e 1958)

\begin{tabular}{|c|c|c|}
\multicolumn{1}{c}{ BMCBPE-n ${ }^{\circ}$ e ano } & CBPE & $5 \%$ \\
\hline $1-1957$ & $85 \%$ & $15 \%$ \\
\hline $2-1957$ & $65 \%$ & $35 \%$ \\
\hline $3-1957$ & $55 \%$ & $45 \%$ \\
\hline $4-1957$ & $40 \%$ & $60 \%$ \\
\hline $5-1957$ & & $32 \%$ \\
\hline & $68 \%$ & $50 \%$ \\
\hline $6-1958$ & $50 \%$ & $45 \%$ \\
\hline $7-1958$ & $55 \%$ & $59 \%$ \\
\hline $8-1958$ & $50 \%$ & $32 \%$ \\
\hline $9-1958$ & $68 \%$ & $50 \%$ \\
\hline $10-1958$ & $50 \%$ & $55 \%$ \\
\hline $11-1958$ & $45 \%$ & $44 \%$ \\
\hline $12-1958$ & $56 \%$ & $20 \%$ \\
\hline $13-1958$ & $80 \%$ & $84 \%$ \\
\hline $14-1958$ & $16 \%$ & $30 \%$ \\
\hline $15-1958$ & $70 \%$ & $45 \%$ \\
\hline $16-1958$ & $55 \%$ & \\
\hline $17-1958$ & & \\
\hline
\end{tabular}

A análise dos territórios ocupados no ano de 1957 revelou o domínio do CBPE frente aos Centros Regionais com uma breve reação na publicação de dezembro (n. 5). É preciso, porém, acrescentar aos percentuais alguns comentários para que os números encontrados possam adquirir a devida proporção. 
O ano de 1957 representou um período de organização geral da instituição tanto no que concerne aos locais de instalação quanto à contratação de profissionais suficientes para dar as mínimas condições de funcionamento a estes órgãos de pesquisas. A ocorrência da primeira reunião da Comissão Consultiva somente em meados de julho de 1957 (um ano e meio após a criação do CBPE) é um indicativo das dificuldades enfrentadas pela instituição para reunir o seu mais alto grau decisório haja vista a Comissão ter sob sua responsabilidade "discutir os planos dos trabalhos dos diferentes C.R., e do C.B., tendo em vista a sua coordenação" (CBPE, 1956). A ata da primeira reunião da Comissão Consultiva assinalou a presença dos Centros Regionais de São Paulo, Minas Gerais, Rio Grande do Sul e Bahia. O CRPE de Recife só entrou em funcionamento a partir de outubro de 1957 sob a direção de Gilberto Freyre.

$\mathrm{O}$ ano de 1958 demonstrou um equilíbrio nos territórios ocupados, à exceção dos números 6, 10, 14 e 16 do BMCBPE, respectivamente dos meses de janeiro, abril, setembro e novembro, que desequilibraram a taxa de espaços ocupados em favor do CBPE. Isto não se deu por acaso. O boletim n. 6 dedicou cinco páginas ao Projeto Maior $n^{\circ} 1$ da UNESCO que fora apresentado durante a 'Conferência Regional sobre Educação Primária Gratuita e Obrigatória na América Latina’ em abril de 1956 - numa síntese preparada por Paulo de Almeida Campos da Divisão de Estudos e Pesquisas Educacionais do CBPE (BMCBPE, n. 6, 1958) 7 .

Por que ocupar as páginas do boletim com uma notícia que estava prestes a completar dois anos? $\mathrm{O}$ Projeto Maior $n^{\circ} 1$ da UNESCO - com verbas da UNESCO e da OEA - iniciou as suas atividades em 1957-1958 com a perspectiva de duração de dez anos. Tinha como objetivo geral a melhoria do ensino primário na América Latina com a devida formação e atualização dos professores. Foi constituído um Comitê Consultivo Intergovernamental para a elaboração e execução do Projeto que na primeira reunião elaborou o plano de aplicação para o biênio 1957-1958. Dentre os pontos do plano, um deles chama atenção: o ponto n. 5.

No Brasil e no Chile funcionarão, em 1958, os cursos de aperfeiçoamento de especialistas em educação (administradores, professôres de pedagogia, inspetores, especialistas em currículo, diretores de escolas normais etc.). No caso brasileiro, o curso funcionará no Centro Regional de Pesquisas Educacionais de São Paulo. Simultâneamente, êsses cursos promoverão trabalhos de pesquisas sôbre problemas do ensino primário. A UNESCO manterá 2 professôres em cada um dêsses cursos. (UNESCO, 1957, p. 15).

Aquilo que a princípio parecia uma notícia descontextualizada foi o projeto mais importante para a sobrevivência do CBPE face aos recursos obtidos para a pesquisa e para a realização de cursos de especialistas da educação e de pesquisas sociais que reforçariam os quadros do CBPE

7 Esta mesma matéria foi publicada na Revista Brasileira de Estudos Pedagógicos, v. 29, n. 70, abr./jun, 1958, p. 84-88.

Ci. Huma. e Soc. em Rev. Seropédica, v. 35 n2, jul. dez., 191-213, 2013. 
e dos Centros Regionais. Cabe acrescentar que inicialmente previsto para ser um projeto de alcance direto dos professores primários da América Latina passou a ter alcance indireto por priorizar a formação de especialistas em educação para lidarem com estes professores.

Outra questão pertinente a este momento foi a busca de uma atuação regional conjunta das Américas. Neste aspecto uma série de projetos, seminários, congressos e instituições buscaram riscar o céu pan-americano em contraponto às políticas da então União Soviética no contexto da Guerra Fria (JUDT, 2008).

QUADRO 02

O BRASIL E AS INSTITUIÇÕES PAN-AMERICANAS EM DIÁLOGO (1956-1964)

\begin{tabular}{|c|c|c|c|c|}
\hline ANO & OEA & PABAEE & CHEAR & OPA \\
\hline 1956 & $\mathrm{x}$ & & & \\
\hline 1957 & $\mathrm{x}$ & $\mathrm{x}$ & & \\
\hline 1958 & $\mathrm{x}$ & $\mathrm{x}$ & $\mathrm{x}$ & $\mathrm{x}$ \\
\hline 1959 & $\mathrm{x}$ & $\mathrm{x}$ & $\mathrm{x}$ & $\mathrm{x}$ \\
\hline 1960 & $\mathrm{x}$ & $\mathrm{x}$ & $\mathrm{x}$ & $\mathrm{x}$ \\
\hline 1961 & & $\mathrm{x}$ & & \\
\hline 1962 & & $\mathrm{x}$ & & \\
\hline 1963 & & $\mathrm{x}$ & & \\
\hline 1964 & & & & \\
\hline
\end{tabular}

As notícias oriundas do BMCBPE e dos outros impressos do Centro Brasileiro de Pesquisas Educacionais - especificamente a Revista Educação e Ciências Sociais - evidenciaram as missões dos colaboradores brasileiros da instituição no exterior e as visitas realizadas ao Brasil de professores e autoridades educacionais de diferentes instituições das Américas. Vale assinalar que a sustentação deste projeto pan-americano passou pelos Estados Unidos da América do Norte com o aporte de verbas e especialistas, pelo Brasil e pelo Chile com o espaço privilegiado dos centros de pesquisa que os colocaram como parceiros preferenciais para a formação de pesquisadores na América Latina.

A realização de eventos e cursos esteve sempre articulada à criação de instituições que conjurassem esforços para a construção e solidificação deste projeto pan-americano. Data desta fase, a criação do CHEAR em 1958 quando a Carnegie Corporation de New York concedeu um auxílio ao Institute of International Education para desenvolver um programa de aproximação pessoal entre os educadores e os homens de Estado das Américas ligados à educação e o estabelecimento de um 
forum para o livre debate dos respectivos problemas de ensino superior nos diferentes países. Em 1960, a Fundação Ford associou-se à Carnegie Corporation para assegurar o funcionamento, por três anos, do referido Conselho (GOUVÊA, 2011).

O Conselho, para conseguir seus objetivos, utilizou os seguintes recursos: Conferências de educadores norte e latino-americanos para a discussão de problemas de ensino superior no hemisfério; visitas pelos educadores participantes às universidades dos países do continente e preparo e realização de seminários e estudos destinados a esclarecer problemas e satisfazer necessidades educacionais identificadas e programadas nas conferências anuais. As reuniões do CHEAR aconteceram em San Juan, Pôrto Rico, em maio de 1958; em 1959 na cidade do México; a do Chile, em 1960 e a de 1961 em San Francisco, nos Estados Unidos. A reunião de 1962 estava marcada para acontecer na cidade do Rio de Janeiro, porém a instabilidade política não permitiu a sua realização em nosso país (TEIXEIRA, 1961).

Utilizo o CHEAR apenas como exemplo de instituição criada para cortar o céu pan-americano em inúmeras viagens de intercâmbio. Outras instituições, mesmo criadas anteriormente, como a UNESCO, a OEA e a Comissão Econômica para a América Latina e Caribe (CEPAL) ${ }^{8}$ contribuíram decisivamente para a execução dos planos e recomendações exaradas por órgãos e assembleias pan-americanas.

Vale destacar que todo o processo de intervenção e legitimação do Centro Brasileiro de Pesquisas Educacionais passou pelos Centros Regionais de Pesquisas Educacionais de São Paulo e da Bahia, como já afirmado, o primeiro por ser um centro de excelência no campo das pesquisas educacionais e sociais e o segundo por ter uma escola de demonstração - a Escola Parque - que seria o destino de excursões pedagógicas de professores e especialistas em educação do Brasil e do exterior. A atuação de tais centro regionais será estudada mais adiante, após a análise das táticas e estratégias utilizadas pelo CBPE para a sua legitimação institucional.

8 Foi criada em 1948 pelo Conselho Econômico e Social das Nações Unidas com o objetivo de incentivar a cooperação econômica entre os seus membros. Ela é uma das cinco comissões econômicas da Organização das Nações Unidas (ONU). 


\section{OS TERRITÓRIOS COMO TÁTICAS E ESTRATÉGIAS DE LEGITIMAÇÃO DO CBPE}

No primeiro semestre de 1958, face às oposições de parte do clero brasileiro em relação à direção de Anísio Teixeira no CBPE/INEP, foi lançado o Memorial dos Bispos do Rio Grande do Sul com uma divulgação de caráter nacional. A resposta às duras críticas lançadas pelo memorial tomou o espaço de sete páginas do no 10 (maio) do BMCBPE. Os textos "Por uma escola organizada e séria para formação básica do povo brasileiro" e o "Manifesto de 529 educadores" expressaram a defesa do ideário do CBPE e do INEP (também sob a gestão de Anísio Teixeira).

Os dois textos tiveram ampla divulgação na imprensa. A resposta não foi dada apenas no BMCBPE. Toda a rede de impressos do CBPE foi acionada com a utilização de textos que com abarcaram a mesma questão: "Educação - problema de formação nacional” na Revista Brasileira de Estudos Pedagógicos (n. 70, 1958) e "Editorial” da Revista Educação e Ciências Sociais (n. 8, 1958). Ambas as publicações eram distribuídas para universidades, bibliotecas, centros de pesquisa nacionais e internacionais com destaque para as organizações de caráter pan-americano (GOUVÊA, 2010, 2010a.)

O no 14 do BMCBPE do mês de setembro de 1958 ampliou a estratégia ao trazer em seis páginas - dentre um total de vinte e sete - a ata completa da $2^{a}$ reunião da Comissão Consultiva do CBPE que solicitava ao presidente da República, Juscelino Kubitschek, a permanência de Anísio Teixeira à frente do CBPE e do INEP. Penso que a legitimação vinda do exterior - inclusive com a presença na referida reunião de Robert Hvighurst, Andrew Pearse e Solon Kimball - representantes da UNESCO - possa esclarecer a redução do território dos CRPEs. Apenas como um possível reforço desta ideia, o no 17 do BMCBPE na sua primeira página trouxe a seguinte notícia: "O Prof. Anísio Teixeira na Organização dos Estados Americanos (OEA)”. As estratégias elaboradas pelos atores internos para a manutenção do diretor do CBPE e do INEP no cargo incluíram a preocupação em divulgar noticias do exterior e de colaboradores do CBPE em terras estrangeiras.

Ainda em 1958, ocorreu a criação da Operação Pan-Americana (OPA) pelo governo Kubitschek que propôs um programa multilateral de assistência ao desenvolvimento econômico da América Latina e que foi submetido à apreciação do governo dos Estados Unidos em 1959. A OPA não obteve êxito, porém, segundo Kramer (2001),

A irrupção de um movimento revolucionário que levou Fidel Castro ao poder em Cuba ( $1^{\circ}$ de janeiro de 1959) fez com que os EUA compreendem-se a urgência de recuperar a legitimidade de sua hegemonia no hemisfério. Fruto desse esforço a Aliança para o 
Progresso, lançada pelo governo do presidente John Kennedy durante a conferência da OEA em Punta del Este, Uruguai, em agosto de 1961, incorporou muitas das ideias originais do programa da OPA ( p. 4.183 et seq.).

Assim, entre luzes e sombras, desenhou-se a rede intelectual que visava unir as três Américas. Mais do que isto, conforme poderá ser observado no quadro 03 , uma intervenção nas políticas públicas educacionais no âmbito nacional nos anos de 1959 e 1960.

\section{QUADRO 03}

TERRITÓRIOS OCUPADOS PELO CBPE E PELOS CRPEs (1959 e 1960)
$\mathrm{BMCBPE}-\mathrm{n}^{\circ}$ e ano
CBPE
CRPEs

\begin{tabular}{|c|c|c|}
\hline 18- 1959 & $72 \%$ & $28 \%$ \\
\hline 19- 1959 & $10 \%$ & $90 \%$ \\
\hline 20- 1959 & $50 \%$ & $50 \%$ \\
\hline 21- 1959 & $60 \%$ & $40 \%$ \\
\hline 22- 1959 & $85 \%$ & $15 \%$ \\
\hline 23- 1959 & $36 \%$ & $64 \%$ \\
\hline 24- 1959 & $35 \%$ & $65 \%$ \\
\hline 25- 1959 & $55 \%$ & $45 \%$ \\
\hline 26- 1959 & $52 \%$ & $48 \%$ \\
\hline 27- 1959 & $90 \%$ & $10 \%$ \\
\hline 28- 1959 & $80 \%$ & $20 \%$ \\
\hline 29- 1959 & $90 \%$ & $10 \%$ \\
\hline $30-1960$ & $85 \%$ & $15 \%$ \\
\hline $31-1960$ & $55 \%$ & $45 \%$ \\
\hline $32-1960$ & $80 \%$ & $20 \%$ \\
\hline $33-1960$ & $56 \%$ & $44 \%$ \\
\hline $34-1960$ & $84 \%$ & $16 \%$ \\
\hline $35-1960$ & $64 \%$ & $36 \%$ \\
\hline $36-1960$ & $88 \%$ & $12 \%$ \\
\hline $37-1960$ & $72 \%$ & $28 \%$ \\
\hline $38-1960$ & $64 \%$ & $36 \%$ \\
\hline $39-1960$ & $75 \%$ & $25 \%$ \\
\hline 40-1960 & $70 \%$ & $30 \%$ \\
\hline $41-1960$ & $88 \%$ & $12 \%$ \\
\hline
\end{tabular}


O cotejamento de todos os boletins publicados em 1959 tornou patente a perda de equilíbrio no espaço de cada território, equilíbrio que tinha sido a tônica do ano anterior. Assim, os números 18, 19, 22, 27, 28 e 29 - metade dos números publicados - conforme o quadro 01- sinalizaram uma ocupação desproporcional em favor do CBPE. À exceção do n. 22 do mês de maio, todos os outros boletins apresentaram extensos relatórios oriundos do CBPE que explica a referida desproporção de espaço.

O ano de 1960 acentuou o predomínio dos territórios ocupados pelo CBPE em proporções absolutamente desiguais e que não apresentam alteração significativa em qualquer dos doze números analisados (n. 30 ao n. 41). A causa desta desproporção é a discussão em torno do projeto de Lei de Diretrizes e Bases da Educação Nacional que se encontrava em debate na Comissão de Educação do Congresso Nacional.

Findo o período de discussões atinentes à Lei de Diretrizes e Bases da Educação Nacional, aprovada em 1961, volta-se a instituição para questões de predominância internacional. Mantém a preocupação com o caráter nacional. Mas, sacrifica os espaços destinados à ambiência regional. O quadro 04 reflete esta escolha institucional.

\section{QUADRO 04}

TERRITÓRIOS OCUPADOS PELO CBPE E PELOS CRPEs (1961 e 1962)

$\mathrm{BMCBPE}-\mathrm{n}^{\circ}$ e ano

CBPE

CRPEs

\begin{tabular}{|c|c|c|}
\hline $42-1961$ & $50 \%$ & $50 \%$ \\
\hline $43-1961$ & $64 \%$ & $36 \%$ \\
\hline $44-1961$ & $85 \%$ & $15 \%$ \\
\hline $45-1961$ & $80 \%$ & $20 \%$ \\
\hline $46-1961$ & $80 \%$ & $20 \%$ \\
\hline $47-1961$ & $84 \%$ & $16 \%$ \\
\hline $48-1961$ & $76 \%$ & $24 \%$ \\
\hline $49-1961$ & $85 \%$ & $15 \%$ \\
\hline $50-1961$ & $72 \%$ & $28 \%$ \\
\hline $51-1961$ & $80 \%$ & $20 \%$ \\
\hline $52-1961$ & $80 \%$ & $20 \%$ \\
\hline $53-1961$ & $80 \%$ & $20 \%$ \\
\hline $54-1962$ & & \\
\hline $55-1962$ & $100 \%$ & $0 \%$ \\
\hline
\end{tabular}




\begin{tabular}{|c|c|c|}
\hline $56-1962$ & $96 \%$ & $4 \%$ \\
\hline $57-1962$ & $76 \%$ & $24 \%$ \\
\hline $58-1962$ & $100 \%$ & $0 \%$ \\
\hline $59-1962$ & $75 \%$ & $25 \%$ \\
\hline $60-1962$ & $92 \%$ & $8 \%$ \\
\hline $61-1962$ & $80 \%$ & $20 \%$ \\
\hline $62-1962$ & $88 \%$ & $12 \%$ \\
\hline $63-1962$ & $100 \%$ & $0 \%$ \\
\hline $64-1962$ & $76 \%$ & $24 \%$ \\
\hline $65-1962$ & $96 \%$ & $4 \%$ \\
\hline
\end{tabular}

O ano de 1961 apresentou entre os territórios a perda de espaço dos Centros Regionais. Os espaços perdidos pelos Centros Regionais foram redirecionados para notícias de caráter geral como as conferências promovidas pela UNESCO, congressos e simpósios nacionais, viagens de Teixeira e outros membros do staff para o exterior e determinações emanadas do CHEAR num nítido redirecionamento das prioridades institucionais: um voo sobre o céu pan-americano.

Portanto, é perceptível que o interesse - mesmo que por motivos óbvios não declarado - passou a ser a abordagem de questões de alcance nacional e internacional, passando as matérias de cunho regional para um segundo plano. Parece oportuno lembrar que um dos elementos diferenciais do $\mathrm{CBPE}$, ao menos no que tange aos seus objetivos fundacionais, se relacionava aos desdobramentos do trabalho nacional em polos regionais num processo de alimentação de mão dupla.

O ano de 1962 teve taxas de ocupação até então não detectadas no BMCBPE, chegando três números a não conter quaisquer notícias dos Centros Regionais - situação inusitada para o periódico. A taxa de ocupação por parte do território intitulado CBPE chegou à marca de 90\% num somatório que deixa entrever que em um total de doze números os Centros Regionais praticamente estiveram alijados em mais de sessenta por cento deles.

No quadro 05, as divisões territoriais referentes aos anos de 1963 e 1964. 


\section{QUADRO 05}

TERRITÓRIOS OCUPADOS PELO CBPE E PELOS CRPEs (1963 e 1964)

\begin{tabular}{|c|c|c|}
\hline $66-1963$ & $88 \%$ & $12 \%$ \\
\hline $67-1963$ & $88 \%$ & $12 \%$ \\
\hline $68-1963$ & $88 \%$ & $12 \%$ \\
\hline $69-1963$ & $76 \%$ & $24 \%$ \\
\hline $70-1963$ & $76 \%$ & $24 \%$ \\
\hline $71-1963$ & $96 \%$ & $4 \%$ \\
\hline $72-1963$ & $96 \%$ & $4 \%$ \\
\hline $73-1963$ & $92 \%$ & $8 \%$ \\
\hline $74-1963$ & $100 \%$ & $0 \%$ \\
\hline $75-1963$ & $100 \%$ & $0 \%$ \\
\hline $76-1963$ & $96 \%$ & $4 \%$ \\
\hline $77-1963$ & $76 \%$ & $24 \%$ \\
\hline $78-1964$ & & \\
\hline $79-1964$ & $100 \%$ & $0 \%$ \\
\hline $80-1964$ & $100 \%$ & $0 \%$ \\
\hline $81-1964 *$ & $100 \%$ & $0 \%$ \\
\hline & $92 \%$ & $8 \%$ \\
\hline
\end{tabular}

Os percentuais de 1963 demonstraram o agravamento do desequilíbrio entre as taxas de ocupação. No total de doze números estudados somente em três deles a taxa pró-CRPE chegou ao patamar de $24 \%$, conseguindo no máximo ocupar uma média ponderada de 10 , $3 \%$. Os números indicam que o afastamento entre as instâncias de atuação institucional

nacional e regional continuaram em decréscimo em conformidade com os anos de 1961 e 1962. A questão que se coloca como desafiadora é pensar o que praticamente paralisou o grupo gestor do CBPE mediante o esgarçamento paulatino da rede que sustentava a instituição. Evidente, que não se trata de elaborar explicações definitivas, mas apontar rotas para a compreensão de tal acontecimento. Nesta tentativa, desejo lembrar aspectos que foram abordados e que entendo auxiliarem o desenvolvimento de uma linha de raciocínio 
que opere a inserção do CBPE no tecido social, econômico e político de seu tempo. Assim, é possível aduzir causas externas ao que venho denominando de esvaziamento, mesmo que esta adição não retire a relevância das causas internas que venho assinalando.

Buscar a pesagem de cada aspecto é peça chave para o entendimento das inflexões, dos afastamentos, dos acúmulos de tarefas em poucas mãos e dos desvios dos objetivos fundacionais, ou seja, das diretrizes que pautaram a criação da instituição na abertura de múltiplas frentes de atuação dos membros do corpo institucional sem a devida atenção para o tanto de interferências e dificuldades que tal diversificação traria para o cumprimento das tarefas primeiras ou cotidianas num equívoco ocasionado pela essência centralizadora do próprio Centro Brasileiro de Pesquisas Educacionais que pelos impressos prega a ausência de restrições hierárquicas em relação aos Centros Regionais, mas que no fazer diário institucional apresentou um teor considerável tanto no aspecto decisório administrativo e pedagógico quanto na determinação dos elementos da instituição responsáveis pelo passos mais importantes a serem dados.

\section{ESCRITAS QUE SE CRUZAM: AS SEÇÕES COMO LUGAR DO REGIONAL, NACIONAL E INTERNACIONAL}

No que concerne às seções, é preciso destacar que o Centro Regional de Pesquisas de São Paulo foi o primeiro a entrar em funcionamento. A fim de sinalizar a devida importância deste centro e as verbas que foram aplicadas na sua sustentação cabe salientar que de acordo com o convênio “o INEP contribuiria para a manutenção do Centro com $20 \%$ da verba anual concedida, pelo Orçamento da República, para a manutenção do CBPE e dos Centros Regionais"(FERREIRA, 2001, p. 27). Portanto, não se trata de o CRPE-SP ser o destino de $20 \%$ das verbas destinadas aos cinco Centros e, sim, de que além de dividir com os outros centros o CRPE-SP teve direito à quinta parte do orçamento anual do próprio CBPE. Estes dados revelam o destaque dado ao CRPE-SP e a aposta de que o mesmo seria um centro de pesquisas de relevância para o Brasil e para a América Latina.

O CRPE-SP foi o centro de 'demonstração' nacional e internacional da execução de pesquisas de caráter sociológico somando- se a este caráter a sua importância na realização de cursos de preparação de especialistas em educação para a América Latina. A centralidade que teria o CRPESP aparece - antes mesmo da aprovação dos planos de criação do CBPE - numa carta enviada por Anísio Teixeira a Fernando de Azevedo datada de 20 de junho de 1955. O trecho a seguir auxilia a compreensão da dimensão desta aposta: 
O prof. Charles Wagley está conosco agora e com ele espero desenvolver os planos do Centro Nacional. Não sabendo se V. já tem a cópia do programa que o professor Otto Klineberg esboçou, também o envio junto com este. É um esboço dos objetivos e organização do Centro daqui, de que o Centro de S. Paulo é o núcleo principal. (VIDAL, 2000, p. 53).

A seção CRPE-SP, no aspecto quantitativo foi a que ocupou o maior número de páginas no BMCBPE - um total de cento e três. Além disto, a seção foi a que obteve a taxa mais efetiva de presença no boletim haja vista não ter se apresentado apenas em 12 boletins de um total de 41 analisados nesta primeira fase. Assim, o BMCBPE refletiu a centralidade do trabalho realizado no referido Centro Regional como registra o quadro 06.

\section{QUADRO 06}

ESPAÇO OCUPADO PELA SEÇÃO - CRPE- SP (número de páginas) - 1957 a 1960

\begin{tabular}{|c|c|}
\hline BMCBPE & número de páginas \\
\hline $1957>$ & 13 \\
\hline & \\
\hline $1958>$ & 34 \\
\hline $1959>$ & 39 \\
\hline $1960>$ & 17 \\
\hline TOTAL: & 103 \\
\hline
\end{tabular}

Importa destacar que a seção durante o período de 1957 a 1959, em cerca de 80\% de suas notícias, teve na descrição de projetos concluídos, relatórios de andamento e de conclusão a base de sua participação no BMCBPE. Esta análise coloca a seção CRPE-SP como a mais afinada com os objetivos que foram definidos para os Centros Regionais de Pesquisa.

O convênio firmado entre o INEP e a USP para a existência do Centro Regional de Pesquisas Educacionais de São Paulo estabeleceu uma mandato de cinco anos para o Diretor do Centro e para os membros do Conselho Deliberativo. Fernando de Azevedo - que dirigiu o Centro desde 
1956 - tomou posse de forma oficial em 1957, portanto a conclusão do seu período de gestão do órgão se daria em 1961, cabendo à reitoria da USP a indicação dos novos dirigentes. Passado o ano de 1961, assumiu a Direção do CRPE-SP o professor Laerte Ramos de Carvalho.

A posse de Laerte Ramos de Carvalho ocorreu no dia 11 de novembro de 1961 em meio a alguns desafios: tentar reconduzir o centro regional à posição de coesão interna, avaliar a produção do ano de 1961, elaborar os planos de trabalho para 1962 e proceder à organização de um novo conselho deliberativo. O conselho deliberativo estruturado por Carvalho evidenciou a compreensão da gravidade deste momento. Eis os membros: Fernando Henrique Cardoso, Octávio Ianni, Maria José Garcia Werebe, Carlos Corrêa Mascaro, Samuel Pfrom Netto e Arrigo Leonardo Angelini. Um conselho composto em sua maioria por elementos que tinham passagens anteriores pelo centro regional e que conheciam os trâmites burocráticos para a elaboração de pesquisas, oferecimento de cursos e seminários de alcance nacional e internacional.

O CRPE-SP - um centro de 'demonstração' nacional e internacional da execução de pesquisas de caráter sociológico - teve no CRPE-BA o seu complemento no âmbito da estrutura planejada para os Centros Regionais haja vista ter o centro baiano a excelência no que se refere à escola de demonstração e escola experimental: a Escola Parque ${ }^{9}$. A escola foi idealizada em 1947 na segunda gestão de Teixeira à frente da Educação na Bahia, mas, somente inaugurada em 1950 e finalizada a sua construção a partir de 1952 com os recursos do Fundo Nacional do Ensino Primário. O quadro 07 informa a presença das notícias oriundas do CRPE-BA no Boletim Mensal do Centro Brasileiro de Pesquisas Educacionais no período de 1957 a 1960.

9 O Centro Educacional Carneiro Ribeiro - conhecido como Escola-Parque - foi idealizado e planejado por Anísio Teixeira, quando secretario de educação da Bahia, (1947/1950), tendo como objetivo revitalizar a escola primária e proporcionar educação, em tempo integral, para crianças da comunidade, numa demonstração de como deve ser a Escola para a classe popular. 


\section{QUADRO 07}

ESPAÇO OCUPADO PELA SEÇÃO - CRPE- BA (número de páginas) - 1957 a 1960

\begin{tabular}{|c|c|}
\hline BMCBPE & número de páginas \\
\hline $1957>$ & 05 \\
\hline $1958>$ & 32 \\
\hline & \\
\hline $1959>$ & 14 \\
\hline & \\
\hline $1960>$ & 03 \\
\hline & 54 \\
\hline
\end{tabular}

A Escola-Parque foi a alma do CRPE-BA ao receber professoras e professores bolsistas do CBPE, do Ponto IV ${ }^{10}$ e das secretarias municipais e estaduais de educação de todo o Brasil, professoras de outras escolas experimentais como a escola Guatemala do D.F., 'excursões pedagógicas' nacionais e visitas internacionais. Carmen Teixeira era a diretora da Escola Parque e, também, do CRPE-BA. A Escola-Parque, a escola de experimentação e os cursos para professores exerceram o predomínio em relação às notícias veiculadas pela seção. Devo considerar que mesmo evidenciando a baixa presença de pesquisas de cunho sociológico, os levantamentos realizados e as experiências permutadas com professores do Brasil e do Exterior consagraram a existência de um processo de elaboração de material pedagógico para a utilização nas escolas e uma ação pedagógica que pudesse mudar a concepção do professor no cotidiano escolar - pontos de destaque nos objetivos expostos no plano de trabalho para a organização dos Centros Regionais.

A seção CRPE-BA em termos quantitativos foi a quarta mais presente no BMCBPE. A análise quantitativa revela que o ano de 1958 foi não só o de maior número de páginas (trinta e duas) como também o de presença regular na publicação (nove em doze possíveis). O inverso ocorreu no ano de 1960 quando a seção esteve representada em apenas dois dos doze boletins possíveis - perfazendo um total de três páginas publicadas numa redução em torno de $90 \%$ em relação ao ano de 1958. Apenas como uma possível pista para o entendimento do desempenho quantitativo

10 Programa de cooperação técnica internacional entre os Estados Unidos e os países Latino-americanos proposto pelo presidente norte-americano Harry Truman em 1949. Recebeu esse nome por ser o quarto ponto do discurso de posse do presidente. O Ponto IV no Brasil foi estabelecido através da assinatura de dois acordos com o governo norte-americano: o Acordo Básico de Cooperação Técnica em 1950 e o acordo de Serviços Técnicos Especiais em 1953. 
da seção no ano de 1960, vale lembrar que este foi o momento que apresentou uma significativa discrepância entre os territórios ocupados pelos CRPEs frente ao CBPE que atingiu todos os cinco centros regionais.

Ao analisar o desempenho desta seção no período de 1957 a 1960, percebe-se que o Centro Regional da Bahia tinha na Escola Parque e demais escolas de demonstração o cerne do seu trabalho. Doze das dezenove presenças da seção na primeira fase tiveram como tema a Escola Parque e a sua proposta de educação integral. O próprio relatório de atividades do primeiro semestre de 1960 do Centro Regional deu o tom do trabalho realizado:

Dedicando-se principalmente à demonstração educacional, através de suas escolas de aplicação e parque, o Centro Regional de Pesquisas Educacionais da Bahia também realiza outras atividades nos seus serviços de pesquisa educacional e de documentação e informação pedagógica. A divisão de pesquisas está atualmente realizando um estudo de amplitude e profundeza sôbre o ensino normal no estado da Bahia. Foram organizados diversos questionários, já distribuídos com os diversos educandários da capital e do interior. A equipe que opera êste trabalho, sob a orientação da prof ${ }^{a}$ Carmen Spínola Teixeira, está constituída pelas professôras Regina Espinheiro Beltrão da Costa, docente de psicologia educacional do curso de Pedagogia da Faculdade Católica de Filosdofia, Carmen Pedroza Cunha e Jorgiza Melo [...] (BMCBPE, n. 38, 1960,).

O relatório apresenta inconsistências. Primeiramente, a redação caracterizou a pesquisa como um acréscimo ou adendo às outras atividades realizadas do CRPE-BA, contrariando as diretrizes estabelecidas para os trabalhos de cada Centro Regional e ainda assinala equivocadamente o termo "divisão de pesquisas" como esfera atuante na estrutura do Centro baiano.

A organização do Centro comportava cinco setores de atividades: aperfeiçoamento do magistério, experimentação pedagógica, documentação e biblioteca, levantamentos e pesquisas e setor de divulgação. Somente em 1958 foram precariamente organizadas a Divisão de Documentação e Informação Pedagógica sob a direção de Luiz Ribeiro de Sena e a Divisão de Aperfeiçoamento do Magistério sob a direção de Carmen Teixeira que também dirigia a Escola Parque. As duas divisões tinham um traço comum: giravam em torno dos cursos oferecidos pela Escola Parque e da divulgação no plano nacional e internacional do trabalho realizado pela mesma.

Cabe aduzir que as divisões responsáveis pelas pesquisas educacionais e pesquisas sociais não lograram organização básica para a sua existência. Nada além de levantamentos e bibliografias compuseram as "pesquisas" propaladas pelo relatório. Tal situação colocou o CRPE-BA em flagrante descompasso em relação aos demais Centros Regionais pois a questão da primazia da Escola Parque que era considerada um rascunho de organização acabou por se configurar como 
arte final. A confirmação de tal assertiva se assenta na seguinte base: o CRPE-BA não apresentou pelas páginas dos impressos da rede CBPE qualquer pesquisa concluída de cunho educacional, sociológico ou antropológico.

Desta forma, afirmo que no período de 1961 a 1964 a mudança de interesse ou a existência de desinteresse pelas questões regionais pode ter determinado o esgotamento do aproveitamento das notícias referentes ao CRPE-BA como penso ter ocorrido em relação aos demais centros, porém em relação especificamente ao congênere baiano arrisco a ocorrência de uma exaustão por repetição de matérias concernentes à Escola Parque. A ideia reside na manutenção do prestígio da Escola Parque no plano pedagógico, mas na sua desvalorização no projeto editorial a ponto da seção CRPE-BA permanecer apartada das páginas do BMCBPE nos últimos vinte e seis números pesquisados, perfazendo mais de dois anos sem se fazer presente no periódico.

\section{CONSIDERAÇÕES FINAIS}

Os estudos e pesquisas educacionais na América Latina nos anos 1950-1960 tiveram no Centro Brasileiro de Pesquisas Educacionais um dos pilares para a solidificação de uma rede panamericana de instituições educativas e voltadas para a pesquisa. Mesmo que o esforço realizado tenha contribuído para um autoesvaziamento do CBPE.

Seria uma postura pouco problematizadora creditar todo este processo de desestruturação institucional ao golpe civil-militar de 1964. É importante asseverar que a perda dos elos institucionais foram também causados pela excessiva acumulação de poderes e compromissos que acabaram por desviar as lideranças para outros projetos que eram incompatíveis com a administração do cotidiano do CBPE e dos CRPEs.

Para além dos compromissos assumidos no âmbito da América Latina, duas outras instituições absorveram os esforços dos quadros do CBPE: O Conselho Federal de Educação e a criação da Universidade de Brasília.

A primeira formação do Conselho Federal de Educação teve a presença dos seguintes intelectuais que também detinham cargos centrais na estrutura do CBPE: Anísio Teixeira, Abgar Renault e Péricles Madureira de Pinho. A fim de facilitar o comparativo, vejamos a composição da equipe responsável pela elaboração do anteprojeto da Universidade de Brasília: Anísio Teixeira, Almir de Castro, Gilberto Freyre e Jayme Abreu. Portanto, três diretores executivos e dois diretores de instituições dirigidas por Teixeira foram acionados para estes dois projetos num momento em que 
outras questões de caráter político e econômico se avolumavam e tornavam cinza o céu brasileiro. A questão que se coloca como desafiadora é pensar: o que praticamente paralisou o grupo gestor do CBPE mediante o esgarçamento paulatino da rede que sustentava a instituição?

Evidente, que não se trata de elaborar explicações definitivas, mas apontar possibilidades para a compreensão de tal acontecimento. Nesta tentativa cabe o desenvolvimento de uma linha de raciocínio que opere a inserção do CBPE no tecido social, econômico e político de seu tempo. Assim, é possível aduzir causas externas ao que venho denominando de autoesvaziamento, mesmo que esta adição não retire a relevância das causas internas já apontadas.

A instabilidade política e econômica foi sentida por uma instituição que, embora estivesse no rol das políticas públicas de cunho especial, estava sujeita aos cortes de orçamento e contingenciamento de despesas num período marcado pelo crescimento da espiral inflacionária. Penso que a operação a ser feita é conceber peso às causas exógenas à instituição sem retirar os entraves de origem interna. Por fim, em meio a estratégias, a memórias, a intelectuais e a redes de sociabilidade, o Centro Brasileiro de Pesquisas Educacionais se revelou uma instituição antenada com o seu tempo. Apenas para efeito de considerações finais, cabe reafirmar o envolvimento do CBPE com instituições panamericanas no período em tela. Anísio Teixeira e seus colaboradores - a partir de 1955 e até 1964 - estiveram envolvidos num intenso movimento de construção de diálogos com instituições de fomento à pesquisa ou propriamente de execução de pesquisas no âmbito das Américas. 


\section{REFERÊNCIAS}

BRASIL. Ministério da Educação e Cultura. Decreto n. 38.460, de 28 de dezembro de 1955. Institui o Centro Brasileiro de Pesquisas Educacionais e centros regionais. Diário Oficial [da] República Federativa do Brasil. Poder Executivo, Rio de Janeiro, DF, Seção 1, p. 23.778, 29 dez. 1955.

BRASIL. Ministério da Educação e Cultura. Revista Educação e Ciências Sociais. Rio de Janeiro: CBPE/INEP/MEC, n. 1 ao n. 21, 1956-1962.

BRASIL. Ministério da Educação e Cultura. Boletim Mensal do Centro Brasileiro de Pesquisas Educacionais. Rio de Janeiro: CBPE/INEP/MEC, n. 1 ao n. 81, 1957-1964.

BRASIL. Ministério da Educação e Cultura. Boletim da Campanha de Aperfeiçoamento de Pessoal de nível Superior. Rio de Janeiro: CBPE/INEP/MEC, n. 1 ao n. 144, 1951-1964.

BRASIL. Ministério da Educação e Cultura. Revista Brasileira de Estudos Pedagógicos. Rio de Janeiro: INEP/MEC, n. 46 ao n. 93, 1952-1964.

BRASIL. Ministério da Educação e Cultura. Conferências Internacionais de educação recomendações (1934-1963). Brasília: MEC/INEP, 1965.

CENTRO BRASILEIRO DE PESQUISAS EDUCACIONAIS. Ministério da Educação e Cultura. Plano de organização do Centro Brasileiro de Pesquisas Educacionais e dos Centros Regionais. Rio de Janeiro: INEP/MEC, 1956.

CERTEAU, M. de. A invenção do cotidiano: 1. a arte do fazer. 10. ed. rev. Petrópolis: Vozes, 2004.

CHARTIER, Roger. A história cultural: entre práticas e representações. Rio de Janeiro: Bertrand, 1990.

FERREIRA, Márcia dos Santos. O Centro Regional de Pesquisas Educacionais de São Paulo (1956/1961). Dissertação de Mestrado, Faculdade de Educação, Universidade de São Paulo, 2001, $194 \mathrm{f}$.

GOUVÊA. Fernando. O estudo do Boletim Informativo da CAPES: contribuições para a historiografia da Educação Superior no Brasil nos anos 1950-1960. Cadernos de História da Educação. Uberlândia: Universidade Federal de Uberlândia, v.11, n. 1, p. 145-164, jan./jun, 2012. 
. A institucionalização da pós-graduação no Brasil; o primeiro decênio da CAPES (1951-1961). Revista Brasileira de Pós-Graduação. Brasília: Fundação Coordenação de Aperfeiçoamento de Pessoal de nível Superior, v.9, n. 17, p. 373-397, julh., 2012a.

GOUVÊA, Fernando. O Boletim Mensal do Centro Brasileiro de Pesquisas Educacionais: o impresso como anúncio de consolidação e prenúncio de declínio institucional. In: Reunião Anual da ANPED, 34, 2011, Natal, R.N.. Anais: Educação e justiça social Rio de Janeiro: ANPED, 2011.

- A análise do Boletim informativo da CAPES: contribuições para a historiografia da Educação Superior do Brasil nos anos 1950 e 1960. In: Reunião Anual da ANPED, 33, 2010, Caxambu, M.G. Anais: Educação no Brasil: o balanço de uma década. Rio de Janeiro: ANPED, 2010 .

O primeiro decênio da CAPES: uma Campanha Extraordinária (1951-1960). Revista Brasileira de Estudos Pedagógicos, Brasília: Instituto Nacional de Estudos e Pesquisas Educacionais Anísio Teixeira, v. 91, n. 229, p. 528-542, set. /dez. 2010a.

. Anísio Teixeira e os treze ministros: a "estratégia doce" de um "apolítico" In: Reunião Anual da ANPED, 32., 2009, Caxambu, M.G. Anais: Sociedade, cultura e educação: novas regulações? Rio de Janeiro: ANPED, 2009.

- Tudo de novo no front: O impresso como estratégia de legitimação do Centro Brasileiro de Pesquisas Educacionais. (1952-1964). Tese de Doutorado, Departamento de Educação, Pontifícia Universidade Católica do Rio de Janeiro. Rio de Janeiro, 2008, 236 f.

Um percurso com os boletins da CAPES: a contribuição de Anísio Teixeira para a institucionalização da pós-graduação no Brasil. Dissertação de Mestrado, Departamento de Educação, Pontifícia Universidade Católica do Rio de Janeiro, 2001, 200 f.

GOUVÊA, Fernando; MENDONÇA, Ana Waleska Polo Campos. A contribuição de Anísio Teixeira para a institucionalização da pós-graduação no Brasil: Um percurso com os boletins da CAPES. Revista Perspectiva, Florianópolis, v. 24, n. 1, p. 111-132, 2006.

JUDT, Tony. Pós-Guerra: uma história da Europa desde 1945. Tradução de José Roberto O’Shea. Rio de Janeiro: Objetiva, 2008. 
KRAMER, Paulo. Operação Pan-Americana. In: ABREU, Alzira Alves de (coord) et al. Dicionário histórico-biográfico brasileiro pós-1930. 2 ed. rev. e atualizada. Rio de Janeiro: Editora FGV, 2001.

ORGANIZACIÓN DE LOS ESTADOS AMERICANOS - OEA. Revista Interamericana de Ciencias Sociales, volumen 2 - número especial, publicação da União Pan-americana, Secretaria General, Organización de los Estados Americanos, Washington, D.C., 1963.

RÉMOND, René. Por uma história política. 2a ed. Rio de Janeiro: Editora FGV, 2003.

TEIXEIRA, Anísio. União intelectual das três Américas. Revista Brasileira de Estudos Pedagógicos, v. 35, n. 82, p.180-183, 1961.

UNESCO. Reunião do Comitê Consultivo Intergovernamental do Projeto Maior $\mathbf{n}^{\circ} 1$ em Havana. Paris: Secretaria da UNESCO, 1957.

VIDAL, Diana Gonçalves (org.). Na batalha da educação: correspondência entre Anísio Teixeira e Fernando de Azevedo (1929-1971). Bragança Paulista: EDUSF, 2000. 